American Journal of Agricultural and Biological Sciences 3 (1): 389-398, 2008

ISSN 1557-4989

(C) 2008 Science Publications

\title{
Geographic Distribution and Genetic Analysis of Physiological Racesof Setosphaeria turcica in Northern China
}

\author{
${ }^{1}$ Jingao Dong, ${ }^{1,2}$ Yongshan Fan, ${ }^{1}$ Xiumei Gui, ${ }^{1}$ Xinlong An, ${ }^{1,3}$ Jifang Ma and ${ }^{3}$ Zhiping Dong \\ ${ }^{1}$ Mycotoxin Laboratory, Agricultural University of Hebei, Baoding, Hebei 071001, China \\ ${ }^{2}$ Department of Life Science, Tangshan Teacher's College, Tangshan, Hebei 063000, China \\ ${ }^{3}$ Institute of Millet Research Agricultural Academy of Hebei, Shijiazhuang, Hebei 050051, China
}

\begin{abstract}
Five hundreds and forty-six isolates of Setosphaeria turcica, the causal agent of Northern Corn Leaf Blight, were collected in 61 corn-growing locations throughout six provinces of Northern China during 2000-2002, to determine their pathogenicity on two sets of host differentials: OH43/Huangzao4, OH43HtlHuangzao4Ht1, OH43Ht2/Huangzao4Ht2, OH43Ht3/Huangzao4Ht3 and $\mathrm{OH} 43 \mathrm{HtN} / \mathrm{Huangzao} 4 \mathrm{Ht} \mathrm{N}$. The isolates were grouped into 13 different physiological races $(0,1,12,3,13,23$, $\mathrm{N}, 1 \mathrm{~N}, 2 \mathrm{~N}, 12 \mathrm{~N}, 3 \mathrm{~N}, 23 \mathrm{~N}$ and $123 \mathrm{~N}$ ) based on their infection types on the host differentials. Incidence analyses indicated that races 0 and race 1 were still dominant in Northern China and took $40.66 \%$ and $18.32 \%$ of total isolates tested respectively, while other races sparsely occurred from 1.28-6.59\%. The emergence of race $123 \mathrm{~N}$ that was toxic to corn lines woth all four existing major resistant genes implies the possibility of present hybrids to loss their resistance in some regions of China. Further analysis of race distribution in Northern China demonstrated that the occurrence and composition of physiological races of S. turcica varied among provinces. Genetic analysis of within and between pathogenic race groups by random amplification polymorphic DNA (RAPD) markers revealed high genetic diversity in $S$. turcica population. Relatively high genetic similarity (70.46-95.12\%) was identified within race groups and the results suggested that race groups were genetically similar within one geographic locations, but genetic migration could possibly happen between some locations which might lead to relative high genetic diversity within one geographic location. The similarity indexes derived from 13 race groups varied from 20.31 to $82.81 \%$ indicating great genetic variation between race groups. The UPGMA dendrograms generated by NTSys software grouped the 13 races into two not very robust but relatively distinct clusters: cluster I $(0,1, \mathrm{~N}, 12,1 \mathrm{~N}, 2 \mathrm{~N}$ and $12 \mathrm{~N})$ and cluster II $(3,13,23,3 \mathrm{~N}, 23 \mathrm{~N}$ and $123 \mathrm{~N})$ with 63.7 and $72.3 \% \mathrm{P}$ value respectively. The cluster analyses suggested that the pathogen might have a great genetic change while mutating to be virulent $\mathrm{Ht3}$ resistant gene, but the details about the mechanisms were remain unaware.
\end{abstract}

key words: Zea mays, corn, Setosphaeria turcica, differential lines, genetic diversity, geographic distribution

\section{INTRODUCTION}

Setosphaeria turcica Leonard and Suggs, anamorph Exserohilum turcicum Leonard and Suggs, the causal agent of Northern Corn Leaf Blight (NCLB), was first reported in Italy in $1876^{[1]}$. It had been one of the most important foliar diseases in corn worldwide ${ }^{[2]}$. S. turcica isolates could be grouped into different physiological races based on their infection types on corn genotypes with different dominant resistant genes $H t 1, H t 2, H t 3$, or $H t N^{[3]}$. Inbred lines carrying these resistant genes had been used in corn breeding program. Because the pathogen's physiological races were greatly related to its pathogenicity, the identification of physiological race was very important in the disease control and the study of corn and pathogen interaction. During the past two decades, an increasing number of novel races had been identified in China $(0$ and 1$)$, in $\operatorname{Mexico}(23 \mathrm{~N}, 23$ and $2 \mathrm{~N})$, in Zambia $(23,23 \mathrm{~N}$ and 0$)$ and Uganda $(0,2, \mathrm{~N}$, $23 \mathrm{~N})^{[4]}$.

In China NCLB was first reported in 1899 and was primarily found in North and Northeast regions of corn production, where the environmental conditions were favorable for disease development ${ }^{[5]}$. The disease did

Corresponding Author: Jingao Dong, Mycotoxin Laboratory, Agricultural University of Hebei, Baoding, Hebei 071001, China 
not become serious until the hybrid corns were widely planted in 1960s since the resistant genes of inbred lines had not been integrated into the hybrids yet. Inbred lines with $H t 1, H t 2, H t 3$ and $H t N$ resistant genes were introduced in corn breeding programs in succession and generated a number of hybrids that could reduce the yield loss due to $S$. turcica. However, the causal fungus rapidly evolved into novel physiological genotypes, such as race 1 , races 23 and $23 \mathrm{~N}$ that led to rapid resistance loss in many hybrids containing $\mathrm{Ht} 1, \mathrm{Ht} 2, \mathrm{Ht} 3$, or $H t N$ gene ${ }^{[6,7]}$. Therefore, the occurrence of novel pathogenic races was continuously a threat to corn with single-locus resistant genes and the work monitoring the occurrence of new pathogenic races of $S$. turcica was always conducted in some NCLB research groups, including the mycotoxin laboratory of Agricultural University of Hebei, China. Since 1999, we sent over 1000 mails to farmers and local researchers in the main corn-grown regions throughout Northern China every year. We asked them collect the leaves infected by NCLB and put them into envelopes before mailed us. We sent students and professional teachers to collect the samples too. In this way, we had built a big bank of $S$. turcica isolates and it made us possible to study the race composition and genetic variance of the causal pathogen of NCLB in Northern China.

The use of RAPD (random amplification of polymorphic DNA) markers was widely used in taxonomy and genetic variance of microbial populations and was ever applied to study the genetic polymorphism of $S$. turcica in Africa and Isalel ${ }^{[8]}$, in tropical and temperate ${ }^{[9]}$ and in Europe ${ }^{[10]}$. The studies enhanced the ability to make inferences about phylogeny and provided vital information about possible genetic mechanisms of S. turcica.

In this study, we will focus on (1) the pathogenic race identification of $S$. turcica in main corn-growing regions of Northern China, (2) the description of occurrence and geographic distribution of the pathogenic races and (3) the analysis of genetic variance within and between the races by RAPD molecular markers.

\section{MATERIALS AND METHODS}

Study area: The research region was located in Northern China where corn was cultivated as one of the main crops (Fig. 1). All corn cultivars were Hybrids since they had been introduced in 1992-1994. The corn was grown as monoculture or in mixed stand that included wheat, soybean or peanuts. Farmers in this region usually bought traditional hybrid seeds for sowing the following year, but more and more farmers bought new hybrid varieties because they could carry them a better harvest at the present. The new hybrids usually carried $\mathrm{Htl}, \mathrm{Ht} 2$ and/or $\mathrm{Ht} 3$ resistant genes, while traditional hybrids only carried $H t l$ resistant gene or carried no gene resistant to $S$. turcica. Therefore, new hybrids were usually more resistant to NCLB than traditional hybrids. Usually a farmer in the region had discontinuous holdings of less than 1 hectare, so traditional hybrids and new hybrids were often mixed grown in one plot.

Isolates collection: In the fall of each year during 2000-2002, corn leaves with typical NCLB symptom were collected from 61 sites in Northern China (Fig. 1). The region included six provinces, i.e. Heilongjiang, Jilin, Liaoning, Hebei (including Beijing and Tianjin city), Shandong and Henan provinces, where NCLB seriously occurred in China. To obtain pure culture from each sample collected in the field, the infected leaves were washed in the distilled water and then cut the lesions including some healthy tissues into small pieces (about $1 \mathrm{~cm}^{2}$ ). The leaf pieces were surface sterilized in a solution of $0.5 \%$ sodium hypochlorite for 2 minutes, followed by washing three times with sterile distilled water. Sterile leaf pieces were then placed in a plate of Potato Dextrose Agar (PDA) and incubated at $22^{\circ} \mathrm{C}$ for 6 to 10 days. S. turcica spores in the cultures were harvested, suspended in sterile distilled water and further diluted up to $10^{-6}$ to obtain single conidium culture. Monoconidial isolates were prepared by picking single germinating conidia on $4 \%$ water agar, multiplying on PDA plates and storing in test tubes containing $5 \mathrm{ml}$ of sterile PDA medium. Usually one isolate per lesion was obtained.

Growth characteristics of each isolate were recorded by measuring colony size at a 2 -day interval for 10 days or longer. No remarkable variation was observed in incubation period between isolates, but there was variation in colony diameters between isolates from different locations. Colony radial growth was influenced by temperature. Some isolates had faster radial growth than others at 20 or $28^{\circ} \mathrm{C}$. The isolates did not exhibit appreciable variation in appearance or in morphology of the colony.

Pathogenic race identification: Two sets of corn differentials, OH43/Huangzao4, OH43HtlHuangzao4Ht1, OH43Ht2/Huangzao $4 \mathrm{Ht} 2$, OH43Ht3/Huangzao4Ht3 and $\mathrm{OH} 43 \mathrm{HtN} / \mathrm{Huangzao} 4 \mathrm{HtN}$, were used to distinguish pathogenic races of $S$. turcica isolates. All differentials were corn-inbred lines generously donated by Professor 


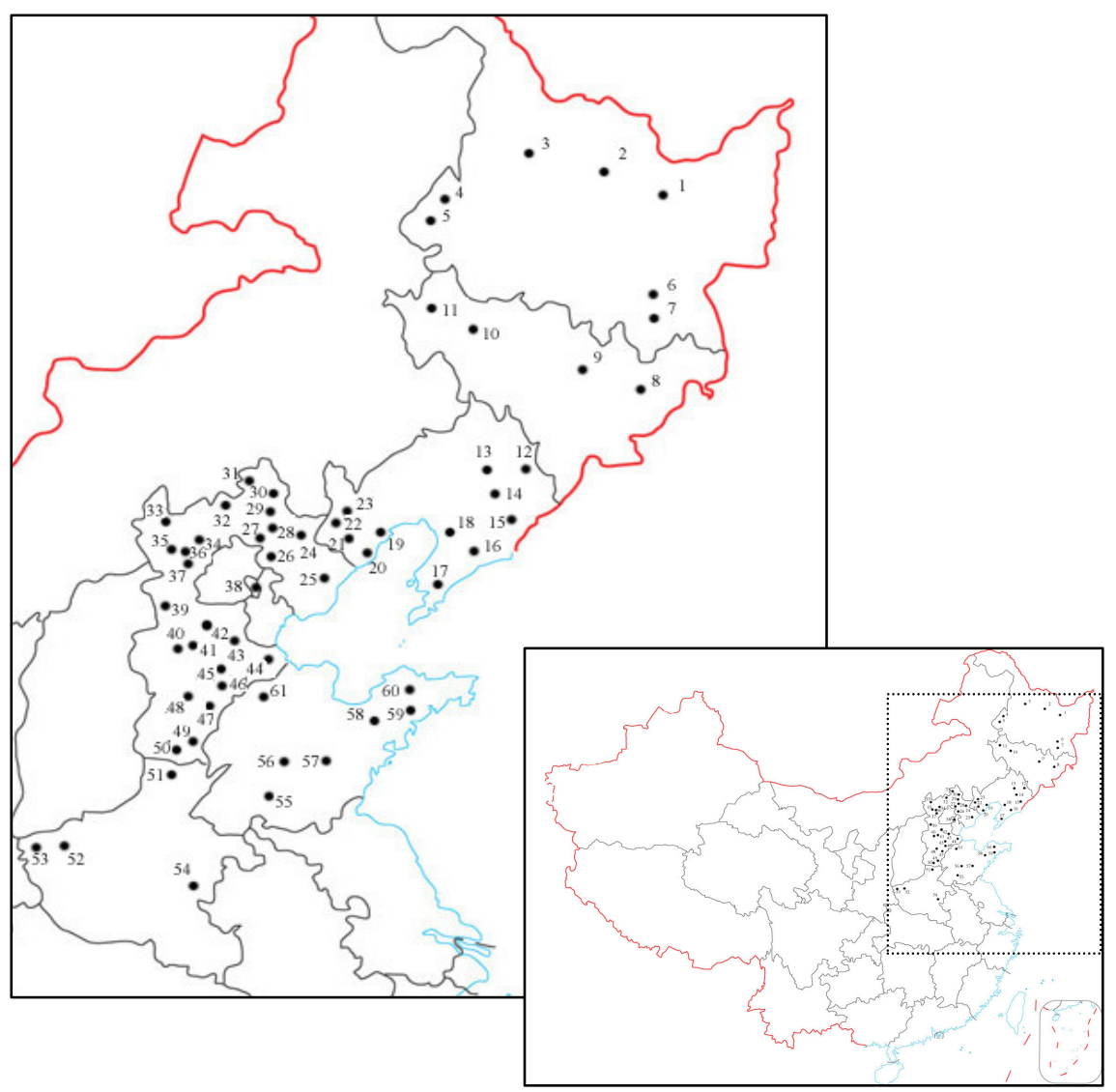

Fig. 1: Collection sites of the NCLB samples in Northern China. Names of sites corresponding to the numbers were in Table 1. The study region includes six important provinces across Northern China: Heilongjiang, Jilin, Liaoning, Hebei(including Beijing and Tianjin city), Shandong and Henan province, where NCLB seriously occurred in China

Fachao Dai from National Microbe Resources Conservation Committee of China. Differentials OH43 and Huanzao4 do not contain any known resistant genes and are susceptible to all races of $S$. turcica. OH43Ht1 and Huanzao $4 \mathrm{Htl}$ are resistant to race 0 because they carry $\mathrm{Ht} l$ resistant gene, which however can be specially overcame by race 1 . OH43Ht2/Huanzao4Ht2, $\mathrm{OH} 43 \mathrm{Ht} 3 /$ Huangzao $4 \mathrm{Ht} 3$ and $\mathrm{OH} 43 \mathrm{HtN} / \mathrm{Huangzao} 4 \mathrm{HtN}$ are particularly susceptible to race 2, race 3 and race $\mathrm{N}$ respectively.

The isolates were cultured on PDA medium in a Petri dish about 7 to 9 days for obtaining their inoculants. The plates were first moistened with a few drops of sterile water and then the conidia were dislodged from the surface of the colonies with a microscope slide. The conidia were washed out with $10 \mathrm{ml}$ of sterile distilled water and then drained into a clean beaker. The suspension was filtered through double-layered gauze and spore concentration was determined using a hemocytometer. Concentration of spores was adjusted to $10^{5}-10^{6}$ per $\mathrm{ml}$ for inoculation of differential hosts. A few of drops of Tween-20 and sucrose $(3.0 \% \mathrm{w} / \mathrm{v})$ were added to the solution just prior to inoculation to improve the spore adhesion on the corn leaves ${ }^{[11]}$.

The sterilized infield loam with about 1 percent composite fertilizer was used to grow the differential host plants in greenhouse at the Agricultural University of Hebei, Baoding, China. Five seeds per line were planted and later three seedlings were kept per pot for inoculation. When the seedlings at a stage with 4-6 leaf (about 4-5 weeks after planting), they were inoculated by spraying spore suspension with a hand-held sprayer. Inoculated plants were immediately covered with polythene sheets up to $48 \mathrm{~h}$ to maintain the moisture. 
Three replicates were designed for each treatment. In order to avoid cross contamination, inoculation area and sprayer were treated with 5\% carbolic acid between the inoculations.

Infection types were classified R-type and S-type and evaluated at 15 days after inoculation on the differentials ${ }^{[12]}$. The sporulating lesions without obvious chlorosis were defined as susceptible reaction (S-type) while non-sporulating lesions with clear chlorosis as resistant reaction (R-type). Physiological races of $S$. turcica were named according to the formula described by Leonard ${ }^{[13]}$. For example, an isolate which is avirulent to differential lines with $H t 1$ and $H t 2$ resistant genes but is virulent to $H t 3$ and $H t N$ genes will be given a virulent formula $H t 1, H t 2 / H t 3, H t N$ and subsequently named as race $3 \mathrm{~N}$.

DNA extraction and RAPD amplification: Genomic DNA was extracted from lyophilized ground mycelium of monoconidial isolates following CTAB (cetyltriethyl ammonium bromide) method ${ }^{[14]}$. DNA relative purity and concentration were determined by electrophoresis with a known concentration marker and fluorometry at the ratio of $\mathrm{OD}_{260} / \mathrm{OD}_{280}$ prior to RAPD amplification [15].

RAPD analysis was employed to determine genetic variation among physiological races of $S$. turcica. PCR amplification was carried out in a $25 \mu \mathrm{l}$ reaction mixture, containing $10 \mathrm{ng}$ of template DNA, $0.2 \mathrm{mM}$ 10-mer random primer (Sangon, Shanghai, China), $100 \mathrm{mM}$ of each dNTP, 2 mM MgCl $2,0.1 \%$ Triton X-100, 0.2 unit of Taq DNA polymerase (TaKaRa, Japan). Twenty-six 10-mer primers (Sangon, Shanghai, China) were used in this study. The amplification reaction was performed in a Biometra 4800 (Whatman Corp., Germany) with a program consisting of a predenature at $94^{\circ} \mathrm{C}$ for $3 \mathrm{~min}$, 40 cycles $\left(94^{\circ} \mathrm{C}\right.$ for $1 \mathrm{~min}$, at $37^{\circ} \mathrm{C}$ for $2 \mathrm{~min}$, at $72^{\circ} \mathrm{C}$ for $2 \mathrm{~min}$ ) and a final extension of $6 \mathrm{~min}$ at $72^{\circ} \mathrm{C}$. Reaction products were electrophoresed on $1.6 \%$ agarose gels at 3 $\mathrm{V} / \mathrm{cm}$ and stained with ethidium bromide before visualization under UV light.

Data analysis: The banding patterns produced by RAPD markers were scored manually using a binary system ( 1 for presence and 0 for absence at each band position). The proportion of common bands was used to analyze the genetic polymorphism within races and calculate similarity index to study genetic variation between races, using the following formula: $\mathrm{Fij}=$ $2 \mathrm{Bij} / \mathrm{Aij}$, where Aij is the numbers of total bands observed for the ith and jth races and $\mathrm{Bij}$ is the common bands observed between the given pair of races ${ }^{[16]}$.

Phylogenetic relationships between races were examined by cluster analysis and phylogenetic dendrograms construction. The dendrograms were generated by the UPGMA method ${ }^{[17]}$ based on the average similarity indices between races using the SAHN program of the NTSYS-pc package ${ }^{[18]}$. The confidence limits of clusters in the UPGMA-based phenograms were determined by performing bootstrap of the binary data using the program WinBoot ${ }^{[19]}$. Each phenogram was reconstructed 2000 times by repeated sampling with replacement and the frequency with which a particular grouping was formed was considered to reflect the robustness of the group.

\section{RESULTS}

Pathogenic races identification: A total of 546 isolates of $S$. turcica were collected from 61 locations across Northern China during 2000-2002 (Table 1). There were 284 isolates collected from Hebei province, 99 isolates from Liaoning, 57 isolates from Heilongjiang, 50 isolates from Shandong, 28 isolates from Henan and 28 isolates from Jilin. During the three years, we attempted to sample as broad geographic areas as possible to obtain an estimate of races distribution of $S$. turcica population throughout Northern China, especially in Hebei province, whose government gave part financial support of the project. However, because the discontinuous distribution of corn-grown areas made it impossible to sample in every corn-grown area, isolates in one study location were collected randomly. Moreover, because of the difficulties of pathogen isolation and fungal conservation for some samples, only 5-8 isolates were collected from some locations (Table 1).

The 546 isolates were inoculated onto the two sets of corn differentials and their reactions to the infection were recorded to identify the races. All differential plants exhibited small pinhead size spots 48-72 $\mathrm{h}$ after inoculation, however, the spots on resistant plants exhibited obvious chlorotic response. Lesions became easy to see at 7-10 days after inoculation. Resistant reaction showed yellowish chlorotic lesions while susceptible lesions were elliptical gray necrotic and sporulating. The lesions on susceptible plants were either water soaked or had dark margins with profuse sporulation. A summary of race identification and sample size for each race were listed in Table 1. 
Am. J. Agril. \& Biol. Sci., 3 (1): 389-398, 2008

Table 1 Collection of Setosphaeria turcica in Northern China and a summary of race identification across sites

\begin{tabular}{|c|c|c|c|c|c|c|c|c|c|}
\hline $\begin{array}{l}\text { Site } \\
\mathrm{No}^{\mathrm{a}} \text {. }\end{array}$ & Province & Site name & $\begin{array}{l}\text { Sample } \\
\text { size }\end{array}$ & $\begin{array}{l}\text { Race } \\
\text { identification }^{\mathrm{d}}\end{array}$ & $\begin{array}{l}\text { Site } \\
\text { No. }\end{array}$ & Province & Site name & $\begin{array}{l}\text { Sample } \\
\text { size }\end{array}$ & $\begin{array}{l}\text { Race } \\
\text { identification }\end{array}$ \\
\hline 1 & Heilong- & Jixian & $7(3,3,1)^{\mathrm{c}}$ & $13(7)^{\mathrm{e}}$ & 32 & \multirow{19}{*}{$\begin{array}{l}\text { Hebei } \\
\text { (cont.) }\end{array}$} & Guyuan & $8(4,4,0)$ & $0(8)$ \\
\hline 2 & jiang & Yichun & $6(3,2,1)$ & $0(6)$ & 33 & & Fuping & $8(3,4,1)$ & $\mathrm{N}(8)$ \\
\hline 3 & $\left(57^{b}\right)$ & Beian & $8(3,3,2)$ & $12(8)$ & 34 & & Chicheng & $11(5,4,2)$ & $1(11)$ \\
\hline 4 & & Gannan & $12(5,3,4)$ & $0(12)$ & 35 & & Zhangjiakou & $8(4,3,1)$ & $1 \mathrm{~N}(8)$ \\
\hline 5 & & Longjiang & $10(6,3,1)$ & $0(10)$ & 36 & & Xuanhua & $14(8,4,2)$ & $13(6), 1(8)$ \\
\hline 6 & & Mudanjiang & $8(4,3,1)$ & $0(8)$ & 37 & & Zhuolu & $7(1,3,3)$ & $2 \mathrm{~N}(7)$ \\
\hline 7 & & Ning'an & $6(4,1,1)$ & $12(6)$ & 38 & & Xianghe & $7(0,2,5)$ & $123 \mathrm{~N}(7)$ \\
\hline 8 & Jilin (28) & Antu & $7(3,3,1)$ & $23 N(7)$ & 39 & & Laiyuan & $31(12,9,10)$ & $13(8), 0(8), 1 \mathrm{~N}(5), 1(10)$ \\
\hline 9 & & Jiaohe & $5(4,0,1)$ & $0(5)$ & 40 & & Dingzhou & $15(7,4,4)$ & $3(8), 23(7)$ \\
\hline 10 & & Gan'an & $7(5,2,0)$ & $1(7)$ & 41 & & Tang county & $8(4,1,3)$ & $0(8)$ \\
\hline 11 & & Baicheng & $9(4,5,0)$ & $0(9)$ & 42 & & Baoding & $13(9,3,1)$ & $1(7), 3(6)$ \\
\hline 12 & Liaoning & Xinbin & $9(5,3,1)$ & $1(9)$ & 43 & & Dacheng & $8(1,5,2)$ & $0(8)$ \\
\hline 13 & (99) & Fushun & $6(3,3,0)$ & $0(6)$ & 44 & & Nanpi & $6(0,0,6)$ & $12(6)$ \\
\hline 14 & & Benxi & $6(5,0,1)$ & $12 \mathrm{~N}(6)$ & 45 & & Raoyang & $5(0,4,1)$ & $1 \mathrm{~N}(5)$ \\
\hline 15 & & Kuandian & $14(6,7,1)$ & $3 \mathrm{~N}(7), 0$ (7) & 46 & & Fucheng & $8(2,4,2)$ & $0(8)$ \\
\hline 16 & & Yongyan & $7(3,0,4)$ & $12(7)$ & 47 & & Zaoqiang & $3(0,3,0)$ & $1 \mathrm{~N}(3)$ \\
\hline 17 & & Pulandian & $7(2,3,2)$ & $3(7)$ & 48 & & Xinji & $7(1,5,1)$ & $\mathrm{N}(7)$ \\
\hline 18 & & Dashiqiao & $7(5,2,0)$ & $\mathrm{N}(7)$ & 49 & & Wei county & $13(7,6,0)$ & $1(13)$ \\
\hline 19 & & Xingcheng & $6(3,3,0)$ & $1(6)$ & 50 & & Ci county & $9(6,3,0)$ & $0(9)$ \\
\hline 20 & & suizhong & $8(3,3,2)$ & $12 \mathrm{~N}(8)$ & 51 & \multirow{4}{*}{$\begin{array}{l}\text { Henan } \\
(28)\end{array}$} & Anyang & $5(4,0,1)$ & $0(5)$ \\
\hline 21 & & Jianchang & $10(4,5,1)$ & $0(10)$ & 52 & & Luoning & $7(1,5,1)$ & $23(7)$ \\
\hline 22 & & Lingyuan & $12(3,3,6)$ & $0(6), 1(6)$ & 53 & & Lingbao & $10(0,6,4)$ & $0(10)$ \\
\hline 23 & & Jianping & $7(3,0,4)$ & $23(7)$ & 54 & & Zhoukou & $6(0,0,6)$ & $0(6)$ \\
\hline 24 & Hebei & Kuancheng & $9(3,4,2)$ & $1(9)$ & 55 & \multirow{8}{*}{$\begin{array}{l}\text { Shandong } \\
(50)\end{array}$} & Jining & $5(1,3,1)$ & $1(5)$ \\
\hline 25 & (284) & Lulong & $8(3,0,5)$ & $0(8)$ & 56 & & Xintai & $8(7,0,1)$ & $0(8)$ \\
\hline 26 & & Xinglong & $15(6,5,2)$ & $0(8), 12 \mathrm{~N}(7)$ & 57 & & Chucheng & $7(1,3,3)$ & $1 \mathrm{~N}(7)$ \\
\hline 27 & & Luanping & $9(4,1,4)$ & $0(9)$ & 58 & & Pingdu & $8(5,0,3)$ & $0(8)$ \\
\hline 28 & & Longhua & $8(3,2,3)$ & $0(8)$ & 59 & & Qixia & $6(3,2,1)$ & $0(6)$ \\
\hline 29 & & Chengde & $23(9,8,6)$ & $\mathrm{N}(6), 0(9), 12(8)$ & 60 & & Rushan & $9(3,2,4)$ & $1(9)$ \\
\hline 30 & & Weichang & $14(7,6,1)$ & $1 \mathrm{~N}(7), 123 \mathrm{~N}(7)$ & 61 & & Ningjin & $7(3,3,1)$ & $3 N(7)$ \\
\hline 31 & & Shangyi & $9(7,2,0)$ & $0(9)$ & Total s & & 546 & & \\
\hline
\end{tabular}

${ }^{a}$ : Site number correspond to those in Fig. $1^{b}:$ Sample size for the province. Isolates included in the study were collected during $2000-2002 .^{c}$ : The first, the second and the third numbers in brackets were isolates collected in 2000, 2001 and 2002 respectively. ${ }^{\text {d }}$ : Two sets of corn differentials,

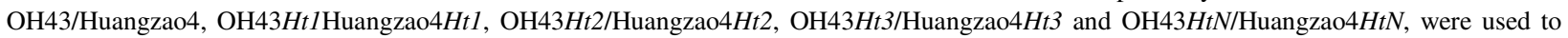
make races identification. Physiological races were rated by the infection types in the differentials described by Hooker (Hooker, 1963) and named according to the formula described by Leonard (Leonard et al., 1989) ${ }^{\mathrm{e}}$ : Numbers in the brackets were the sample size of the corresponding races

Thirteen physiological races $(0,1,12,3,13,23, \mathrm{~N}$, $1 \mathrm{~N}, 2 \mathrm{~N}, 12 \mathrm{~N}, 3 \mathrm{~N}, 23 \mathrm{~N}$ and $123 \mathrm{~N})$ were distinguished according to their infection types in the differentials. Among them, race $2 \mathrm{~N}$ was firstly identified in China and races $13,3,1 \mathrm{~N}, 3 \mathrm{~N}$ and $123 \mathrm{~N}$ were firstly reported in the worldwide corn planting area. The isolates in the same race population had the identical infection types in the two sets of host differentials, although the disease severity might be different between the two sets of differentials.

Races geographic distribution and occurrence frequency: Sample size and occurrence frequency of pathogenic races of $S$. turcica identified in the six provinces of Northern China were listed in Table 2 . There were 11 races $(0,1,12,3,13,23, N, 1 \mathrm{~N}, 2 \mathrm{~N}, 12 \mathrm{~N}$ and $123 \mathrm{~N})$ identified in Hebei province, 8 races $(0,1,12$, $3,23, \mathrm{~N}, 12 \mathrm{~N}$ and $3 \mathrm{~N})$ in Liaoning province, 2 races $(0$ and 23) identified in Henan province, 3 races $(0,12$ and
13 ) in Heilongjiang province, 3 races $(0,1$ and $23 \mathrm{~N})$ in Jilin province, 4 races $(0,1,1 \mathrm{~N}$ and $3 \mathrm{~N})$ in Shandong province.

The occurrence frequency of different pathogenic races identified in Northern China varied from 1.28 to $40.66 \%$ (Table 2). Race 0 and race 1 still dominated in Northern China and they took 40.66 and $18.32 \%$ of total isolates tested respectively. Other races sparsely occurred with the occurrence frequency of only $1.28-6.59 \%$ : race $12(6.41 \%)$, race $1 \mathrm{~N}(6.41 \%)$, race $\mathrm{N}$ $(5.13 \%)$, race $3(3.85 \%)$, race $13(3.85 \%)$, race 23 $(3.85 \%)$, race $12 \mathrm{~N}(3.85 \%)$, race $3 \mathrm{~N}(2.56 \%)$, race $123 \mathrm{~N}$ $(2.56 \%)$, race $2 \mathrm{~N}(1.28 \%)$ and race $23 \mathrm{~N}(1.28 \%)$.

RAPD analysis of $S$. turcica isolates: Sixteen reproducible polymorphic RAPD primers were selected from 26 RAPD primers to amplify random sequences from the genomic DNA of isolates belonging to 13 races of $S$. turcica (Table 3 ). The other 10 primers had 
Am. J. Agril. \& Biol. Sci., 3 (1): 389-398, 2008

Table 2: Sample size and occurrence frequency of pathogenic races of S. turcica in the provinces of Northern China

\begin{tabular}{|c|c|c|c|c|c|c|c|c|c|c|c|c|c|c|c|}
\hline \multicolumn{2}{|c|}{ Race distribution } & \multirow{2}{*}{$\begin{array}{l}0 \\
100.00\end{array}$} & \multirow{2}{*}{$\begin{array}{l}1 \\
58.00\end{array}$} & \multirow{2}{*}{$\begin{array}{l}12 \\
14.00\end{array}$} & \multirow{2}{*}{$\frac{3}{14.00}$} & \multirow{2}{*}{$\frac{13}{14.00}$} & \multirow{2}{*}{$\frac{23}{7.00}$} & \multirow{2}{*}{$\frac{\mathrm{N}}{21.00}$} & \multirow{2}{*}{$\frac{1 \mathrm{~N}}{28.00}$} & \multirow{2}{*}{$\frac{2 \mathrm{~N}}{7.00}$} & \multirow{2}{*}{$\frac{12 \mathrm{~N}}{7.00}$} & \multirow{2}{*}{$\frac{3 \mathrm{~N}}{0.00}$} & \multirow{2}{*}{$\frac{23 \mathrm{~N}}{0.00}$} & \multirow{2}{*}{$\frac{123 \mathrm{~N}}{14.00}$} & \multirow{2}{*}{$\frac{\sum}{284.00}$} \\
\hline Hebei & Sample size & & & & & & & & & & & & & & \\
\hline & Frequency $(\%)^{\mathrm{a}}$ & 18.32 & 10.62 & 2.56 & 2.56 & 2.56 & 1.28 & 3.85 & 5.13 & 1.28 & 1.28 & 0.00 & 0.00 & 2.56 & 52.01 \\
\hline \multirow[t]{2}{*}{ Liaoning } & Sample size & 29.00 & 21.00 & 7.00 & 7.00 & 0.00 & 7.00 & 7.00 & 0.00 & 0.00 & 14.00 & 7.00 & 0.00 & 0.00 & 99.00 \\
\hline & equency (\%) & 5.31 & 3.85 & 1.28 & 1.28 & 0.00 & 1.28 & 1.28 & 0.00 & 0.00 & 2.56 & 1.28 & 0.00 & 0.00 & 18.13 \\
\hline \multirow[t]{2}{*}{ Henan } & & 21.00 & 0.00 & 0.00 & 0.00 & 0.00 & 7.00 & 0.00 & 0.00 & 0.0 & 0.00 & 0.00 & 0.00 & $0 .($ & 28.00 \\
\hline & Frequency $(\%)$ & & 0.00 & 0.00 & 0.00 & 0.00 & 1.28 & 0.00 & 0.00 & 0.00 & 0.00 & 0.00 & 0.00 & 0.00 & 5.13 \\
\hline \multirow[t]{2}{*}{ Heilongjiang } & Sample size & 36.00 & 0.00 & 14.00 & 0.00 & 7.00 & 0.00 & 0.00 & 0.00 & 0.00 & 0.00 & 0.00 & 0.00 & 0.00 & 57.00 \\
\hline & Freq & & 0.00 & 2.56 & 0.00 & 1.28 & 0.00 & 0.00 & 0.00 & 0.0 & 0.00 & 0.00 & & 0.00 & 10.44 \\
\hline \multirow[t]{2}{*}{ Jilin } & & 14.00 & 7.00 & 0.00 & 0.00 & 0.00 & 0.00 & 0.00 & 0.00 & 0.0 & 0.00 & 0.00 & 7.00 & 0.00 & 28.00 \\
\hline & $(\%)$ & 2.56 & 1.28 & 0.00 & 0.00 & 0.00 & 0.00 & 0.00 & 0.00 & 0.00 & 0.00 & 0.00 & 1.28 & 0.00 & 5.13 \\
\hline \multirow[t]{2}{*}{ Shandong } & Samp & 22.00 & 14.00 & 0.00 & 0.00 & 0.00 & 0.00 & 0.00 & 7.00 & 0.00 & 0.00 & 7.00 & 0.00 & 0.00 & 50.00 \\
\hline & Frequency $(\%)$ & 4.03 & 2.56 & 0.00 & 0.00 & 0.00 & 0.00 & 0.00 & 1.28 & 0.00 & 0.00 & 1.28 & 0.00 & 0.00 & 9.16 \\
\hline \multirow[t]{2}{*}{$\Sigma$} & Sample size & 222.00 & 100.00 & 35.00 & 21.00 & 21.00 & 21.00 & 28.00 & 35.00 & 7.00 & 21.00 & 14.00 & 7.00 & 14.00 & 546.00 \\
\hline & Frequency $(\%)$ & 40.66 & 18.32 & 6.41 & 3.85 & 3.85 & 3.85 & 5.13 & 6.41 & 1.28 & 3.85 & 2.56 & 1.28 & 2.56 & 100.00 \\
\hline
\end{tabular}

${ }^{\mathrm{a}}$ : The percentage of sample size of the race population in the total 546 isolates tested

Table 3. Information on RAPD primers in the study

\begin{tabular}{|c|c|c|c|c|c|}
\hline Primer code ${ }^{a}$ & Sequence $5^{\prime}-3^{\prime}$ & Average RAPD bands & Primer code & Sequence $5{ }^{\prime}-3^{\prime}$ & Average RAPD bands \\
\hline $\mathrm{S} 15^{\mathrm{b}}$ & GGAGGGTGTT & 8 & S2037 & ACACCGTGCC & \\
\hline $\mathrm{S} 17^{\mathrm{b}}$ & AGGGAACGAG & 6 & $\mathrm{~S} 2042^{\mathrm{b}}$ & ACAGTAGCGG & 8 \\
\hline S33 & CAGCACCCAC & & $\mathrm{S} 33^{\mathrm{b}}$ & CAGCACCCAC & 7 \\
\hline S45 & TGAGCGGACA & & $\mathrm{S} 43611^{\mathrm{b}}$ & GAGCCCTCCA & 9 \\
\hline $\mathrm{S} 2003^{\mathrm{b}}$ & GTGCGAGAAC & 6 & S43612 & AGCGTGTCTG & \\
\hline S2005 & TGCGTTCCAC & & $\mathrm{S} 43613^{\mathrm{b}}$ & CTGAGACGGA & 7 \\
\hline S2021 & ACACTGGCTG & & $\mathrm{S} 43618^{\mathrm{b}}$ & AGGGCCGTCT & 8 \\
\hline S2023 & TCACGTGGCT & & $\mathrm{S} 43623^{\mathrm{b}}$ & ACTGGGACTC & 8 \\
\hline S2024 & ACCAGGTCAC & & $\mathrm{S} 43624^{\mathrm{b}}$ & AGCGTCCTCC & 6 \\
\hline $\mathrm{S} 2025^{\mathrm{b}}$ & GGGCCGAACA & 8 & S43625 & ACGACCGACA & \\
\hline $\mathrm{S} 2026^{\mathrm{b}}$ & CTGAAGCTGG & 7 & $\mathrm{~S} 43627^{\mathrm{b}}$ & GTCAGGGCAA & 8 \\
\hline $\mathrm{S} 2027^{\mathrm{b}}$ & GAAGGCTGGG & 6 & $\mathrm{~S} 45^{\mathrm{b}}$ & TGAGCGGACA & 6 \\
\hline S2031 ${ }^{b}$ & TGCGGGTTCC & 8 & Total RAPD bands & 116 & \\
\hline S2035 & AAGTGCCCTG & & Average bands for e & ach primer & 7.25 \\
\hline
\end{tabular}

${ }^{a}$ : Primers purchased from Sangon Technologies Inc. Shanghai, China. ${ }^{b}:$ Primers exhibited reproducible polymorphism in RAPD analyses of races of S. turcica

no RAPD amplicons for some samples, so they were not selected to analyze the genetic diversity within and between races.

The sample size of each race population was listed in Table 4. Each race population comprised about 2-5 isolates in every location where the race was identified. However, if the race was only found in one location, for example, race $2 \mathrm{~N}$ was only found in Zhuolu county of Hebei province, race $23 \mathrm{~N}$ was only found in Antu city of Jilin province, 5-7 isolates were selected to analyze their genetic diversity within the races.

All of the 16 polymorphic primers gave clear DNA bands on the agarose gels as shown in Fig. 2. A total of 116 bands and an average of 7.25 bands per primer were obtained by RAPD amplification (Table 3 ).

Variation within races: Among all races, the average percentages of common bands were $66.12 \%$ for RAPD analysis. The overall similarity values indicated the detectability of genetic polymorphism within races. The average percentage of common bands within races 0,1 , $12 \mathrm{~N}, 1 \mathrm{~N}, 12, \mathrm{~N}, 3 \mathrm{~N}, 13,123 \mathrm{~N}, 3,23,23 \mathrm{~N}$ and $2 \mathrm{~N}$ were 70.46, 76.00, 78.41, 79.49, 81.48, 83.12, 84.34, 85.51, $87.18,88.61,89.19,90.28$ and $95.12 \%$, respectively (Table 4), indicating that the races had from high to low tendency to have intrasubspecific variation.

Table 4: Average percentages of common bands within races as revealed by RAPD analyses

\begin{tabular}{lcc}
\hline & $\begin{array}{c}\text { Total isolates } \\
\text { compared }\end{array}$ & $\begin{array}{c}\text { Average percentage of } \\
\text { common bands (\%) }\end{array}$ \\
\hline Among all races & 183 & 66.12 \\
Within race 0 & 56 & 70.45 \\
Within race 1 & 24 & 76.00 \\
Within race 12N & 6 & 78.41 \\
Within race 1N & 18 & 79.49 \\
Within race 12 & 15 & 81.48 \\
Within race N & 8 & 83.12 \\
Within race 3N & 10 & 84.34 \\
Within race 13 & 9 & 85.51 \\
Within race 123N & 8 & 87.18 \\
Within race 3 & 9 & 88.61 \\
Within race 23 & 8 & 89.19 \\
Within race 23N & $7^{\text {a) }}$ & 90.28 \\
Within race 2N & $5^{\text {a) }}$ & 95.12
\end{tabular}

Except a): isolates from one location, the other numbers indicates 2-5 isolates from one location where the corresponding race was identified in Northern China 

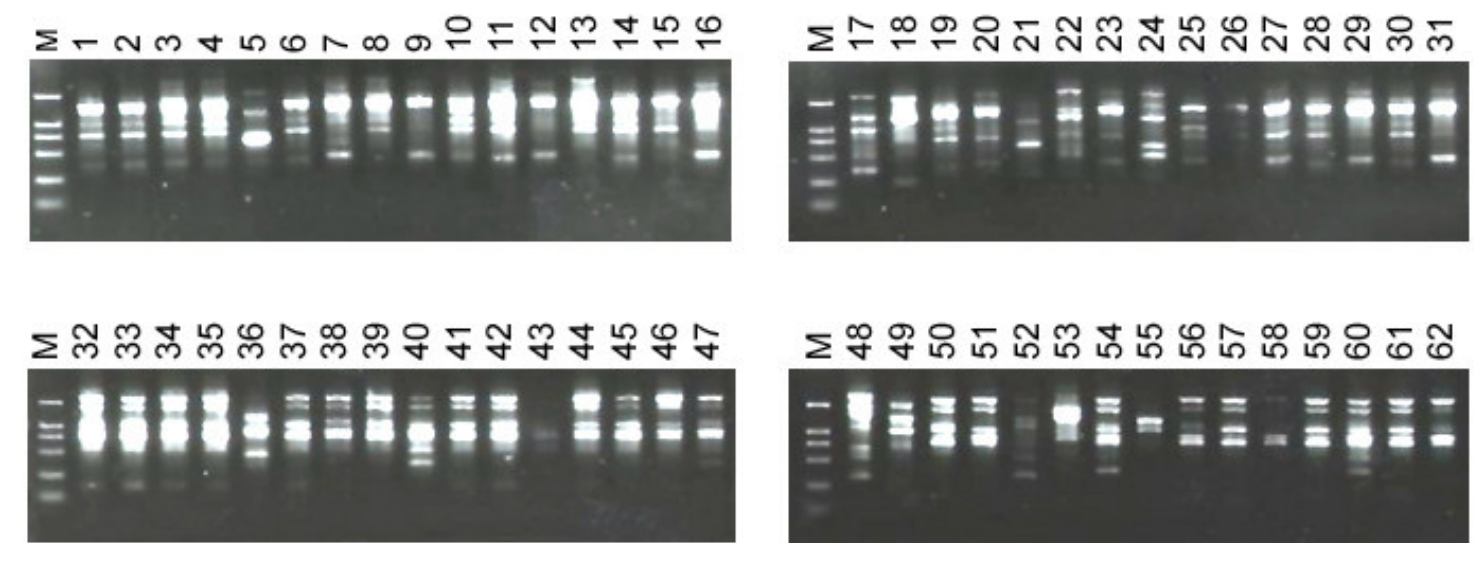

Fig. 2: RAPD band pattern of 62 isolates of S. turcica. Amplification pattern was with S18 primer. M: DL2000 molecular DNA marker. 1-62: isolates of S. turcica from different districts of China

Table 5: Comparison of similarity indexes between physiological race groups as revealed by RAPD analysis

\begin{tabular}{|c|c|c|c|c|c|c|c|c|c|c|c|c|c|}
\hline & Race 0 & Race N & Race $1 \mathrm{~N}$ & Race 12 & Race $12 \mathrm{~N}$ & Race 1 & Race $2 \mathrm{~N}$ & Race $3 \mathrm{~N}$ & Race $23 N$ & Race $123 \mathrm{~N}$ & Race 13 & Race 3 & Race 23 \\
\hline Race 0 & 100.00 & & & & & & & & & & & & \\
\hline Race N & 65.63 & 100.00 & & & & & & & & & & & \\
\hline Race 1N & 73.44 & 73.44 & 100.00 & & & & & & & & & & \\
\hline Race 12 & 71.88 & 76.56 & 71.88 & 100.00 & & & & & & & & & \\
\hline Race $12 \mathrm{~N}$ & 65.63 & 76.56 & 78.13 & 68.75 & 100.00 & & & & & & & & \\
\hline Race 1 & 82.81 & 68.75 & 71.88 & 73.44 & 64.06 & 100.00 & & & & & & & \\
\hline Race $2 \mathrm{~N}$ & 51.56 & 59.38 & 64.06 & 56.25 & 57.81 & 59.38 & 100.00 & & & & & & \\
\hline Race 3N & 42.19 & 40.63 & 46.88 & 48.44 & 31.25 & 50.00 & 56.25 & 100.00 & & & & & \\
\hline Race $23 \mathrm{~N}$ & 42.19 & 37.50 & 42.19 & 39.06 & 35.94 & 50.00 & 53.13 & 71.88 & 100.00 & & & & \\
\hline Race $23 \mathrm{~N}$ & 35.94 & 35.94 & 20.31 & 34.38 & 28.13 & 35.94 & 43.75 & 67.19 & 68.75 & 100.00 & & & \\
\hline Race 13 & 45.31 & 42.19 & 56.25 & 50.00 & 40.63 & 53.13 & 53.13 & 67.19 & 64.06 & 46.88 & 100.00 & & \\
\hline Race 3 & 43.75 & 43.75 & 35.94 & 40.63 & 37.50 & 54.69 & 54.69 & 73.44 & 79.69 & 70.31 & 62.50 & 100.00 & \\
\hline Race 23 & 39.06 & 37.50 & 39.06 & 42.19 & 40.63 & 40.63 & 40.63 & 76.56 & 68.75 & 67.19 & 60.94 & 70.31 & 100.00 \\
\hline
\end{tabular}

Comparing the above results with the geographic distribution of race groups in Table 1 (race 0, 28 sites; race 1,11 sites; race $12 \mathrm{~N}, 3$ sites; race $1 \mathrm{~N}, 6$ sites; race 12, 5 sites; race N, 4 sites; race 13, 3 sites; race 3, 3 sites; race 23, 3 sites; race $3 \mathrm{~N}, 2$ sites; race $123 \mathrm{~N}, 2$ sites; race $23 \mathrm{~N}, 1$ site; race $2 \mathrm{~N}, 1$ site), it could be derived that the geographic distribution of the races might contribute to the genetic variation within race groups, i.e. the broader geographic distribution of the race groups, the more genetic variation within them. The only possible exception was race $12 \mathrm{~N}$ group, suggesting that genetic migration could happen between different locations and lead to relative high genetic diversity within one geographic location.

Variation between races: In order to clarify the variation between races, the isolates belonging to the same pathogenic race were treated as one group. Among all race groups, the band patterns were scored and subjected to calculate the similarity indexes between race groups. The indexes derived from 13 race groups varied from 20.31 to $82.81 \%$ (Table 5). These results revealed that great genetic differentiation generated between different race groups, which agreed with the conclusions of previous studies ${ }^{[8]}$.

In order to elucidate the phylogenetic relationships between race groups, a phylogenetic dendrogram was generated by the UPGMA method ${ }^{[17]}$ based on the average similarity coefficient between race groups using the SAHN program of the NTSYS-pc package ${ }^{118]}$. The phenogram was reconstructed 2000 times using the program WinBoot ${ }^{[19]}$ and the frequency was considered to reflect the robustness of the clusters (Fig. 3).

Four clusters, A (including race groups $0,1, \mathrm{~N}, 12$, $1 \mathrm{~N}$ and $12 \mathrm{~N}$ ), B (race group $2 \mathrm{~N}$ ), $\mathrm{C}$ (including race groups $3,13,23,3 \mathrm{~N}$ and $23 \mathrm{~N}$ ) and $\mathrm{D}$ (race group $123 \mathrm{~N}$ ), were resolved at the 0.16 similarity level. Clusters B and $\mathrm{D}$ consisted of only one race group each, so bootstrap values for these clusters were not applicable. In order to determine the bootstrap values for clusters B and D as it appears in the UPGMA dendrogram, two bigger clusters, cluster I (including clusters A and B) and 


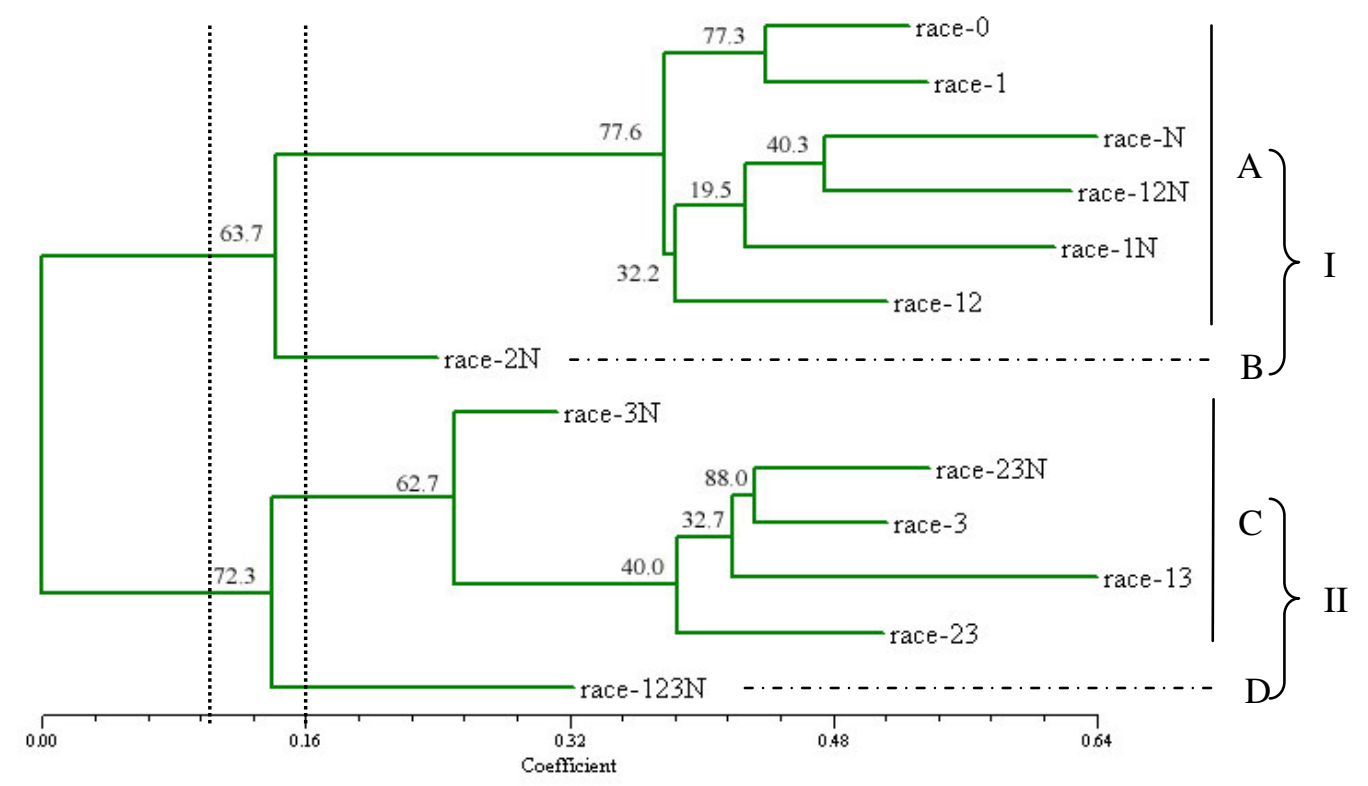

Fig. 3: UPGMA dendrogram of pathogenic race groups of Setosphaeria turcica based on DNA banding patterns revealed by RAPD analysis. Bootstrap $P$ values are indicated at the corresponding node for each cluster. Four clusters, A-D, are resolved at the 0.16 similarity level. Clusters B and D consist of only one race group each, so bootstrap values for these clusters are not applicable. In order to determine the bootstrap values for group B as it appears in the UPGMA dendrogram, two clusters, I and II, are resolved at the 0.10 similarity level. Although clusters I and II had a relatively low P value, $63.7 \%$ and $72.3 \%$ respectively, they are still quite distinct from each other

clusters II (including clusters C and D), were resolved at the 0.10 similarity level. Although clusters I and II had a relatively low p-value, 63.7 and $72.3 \%$ respectively, they were still quite distinct from each other.

\section{DISCUSSION}

Temperature and humidity were two important factors affecting the corn growth and the pathogenicity of the isolates. Even in environment-controlled greenhouses, late spring and early autumn was appropriate time for the laboratory inoculation. Growth stage of corn seedlings also affectws plant response to $S$. turcica infection. Seedlings with 4-6 leaves were consistently used in this study.

Leath and Pedersen in $1986^{[20]}$ found it impossible to accurately assess lesion number, type and size due to some lines exhibited multitudes of small chlorotic lesions. Only necrotic lesions were assessed for size. Therefore only two reactions were recorded in this study, i.e. the resistant lesions and the susceptible lesions.

Distribution of 13 physiological races $(0,1,12,3$, $13,23, \mathrm{~N}, 1 \mathrm{~N}, 2 \mathrm{~N}, 12 \mathrm{~N}, 3 \mathrm{~N}, 23 \mathrm{~N}$ and $123 \mathrm{~N})$ of $S$. turcica varied among the provinces covered in this study. Except for races $3 \mathrm{~N}$ and $23 \mathrm{~N}$, all other 11 races were detected in Hebei province, in which the most physiological races of $S$. turcica were found. Eight races were found in Liaoning province, 4 races in Shandong province, 3 races in Jilin and Heilongjiang provinces and 2 races in Henan province. However, only physiological race 0 was found at 28 locations of all 6 provinces covered in this study. Race 1 was also very popular and could be found at 11 locations in Hebei, Liaoning, Jilin and Shandong provinces. Race $1 \mathrm{~N}$ were found at 6 locations in which 5 locations were in Hebei province, the other one location were in Shandong province. Race 12 occurred at 5 locations in Hebei, Liaoning and Heilongjiang provinces. Race $3, \mathrm{~N}$ and $12 \mathrm{~N}$ were only found in Hebei and Liaoning provinces. Race 13 occurred at 2 locations in Hebei province and 1 location in Heilongjiang province. Race 23 was found at 3 locations in Hebei, Liaoning and Henan provinces. Race $3 \mathrm{~N}$ was found at Liaoning province and Shandong province. Race $23 \mathrm{~N}$ and $2 \mathrm{~N}$ were only found at Antu city in Jilin province and at Zhuolu county in Hebei province respectively. Race $123 \mathrm{~N}$, virulent to corns with all four existed $H t$ resistant genes, was found at Weichang county and Xianghe county in Hebei province (Table 1 and Table 2). The existence of race $123 \mathrm{~N}$ had given us a signal that the pathogen had been differentiating at all times and could be mutated into more virulent and more dangerous. 
Introduction of $\mathrm{Ht}$ gene into China in 1970s made a tremendous impact on maize production, but the situation had soon changed because of new pathogenic races of $S$. turcica evolved. Wu et al ${ }^{[21]}$ first reported the existence of $S$. turcica race 1 in Dandong district of Liaoning province. Race 23 was first found in Yunnan province in $1989^{[6]}$ and subsequently identified in Guizhou province in $1993^{[22]}$. Although new races had been reported since then, race 0 was dominant one during the last two decades. In 1993, Chen ${ }^{[5]}$ reported that race 1 became dominant genotype of $S$. turcica in Liaoning province and a large volume of research were conducted to understand the occurrence and distribution of those races ${ }^{[2,11,20,22-25]}$. In this study, the race 0 was still dominant in northern China with the average occurrence of $40.66 \%$, followed by race $1(18.32 \%)$. The other races occurred only in certain locations with no more than $7 \%$ occurrence frequency.

Races 0 and 1 had been dominant ones in China for more than 20 years with little changes in their occurrence, indicating that the pathogen was a population with high speed of genetic variance but at a stable pace. Many factors might contribute such variation, such as the frequently change of hybrid cultivars and cultivation system, the rapid changes in hybrids composition, the change of environmental temperature and so on. It could be predicated that the dominance of races 0 and 1 might continue for several years in Northern China.

In the past two decades, NCLB was one of the most important diseases of maize (Zea mays L) in warm and humid part of the world ${ }^{[26,27]}$. In Africa, NCLB was reported to be widespread and destructive disease of maize in Ethiopia, Tanzania and Uganda ${ }^{[28-30]}$. In the United States, northern leaf blight was the major disease of maize ${ }^{[31]}$. However, after the seven races $0,1,2, \mathrm{~N}, 23$, $2 \mathrm{~N}$ and $23 \mathrm{~N}$ were reported ${ }^{[4,13]}$, even the great variation in genetic diversity of the pathogen was found within or between states or regions ${ }^{[9,32]}$, only Oliari et al ${ }^{[33]}$ reported three new races including two new virulent factors in S. turcica. One of the major reasons for the little discovery of new physiological races could be predicated as the even distribution of corn lines with different resistant genes leading to balanced genetic differentiation in Setosphaeria turcica, which could be suggested by the genetic variation studies within and between race groups in this project.

The studies on the genetic variation within and between race groups in Northern China by RAPD analysis revealed that the pathogen's population had high genotypic diversity, which was identical to the studies of genetic structure of Setosphaeria turcica populations in tropical and temperate climates ${ }^{[9]}$. Genetic variation within race groups suggested that the race groups were genetic similar within one location, but it could not be excluded that genetic migration could happen between locations. Genetic variation between race groups was revealed by the phylogenetic relationship study using a UPGMA dendrogram generated by NTSys software and confirmed by WinBoot software. Although having not very robust confidence, 63.7 and $72.3 \%$ respectively, two distinct clusters were resolved at 0.1 similarity level: cluster I $(0,1, \mathrm{~N}, 12,1 \mathrm{~N}, 2 \mathrm{~N}$ and $12 \mathrm{~N})$ and cluster II (3, $13,23,3 \mathrm{~N}, 23 \mathrm{~N}$ and $123 \mathrm{~N}$ ). Race group $2 \mathrm{~N}$ was relatively distinct from other race groups with $77.6 \%$ $\mathrm{p}$-value in cluster I and race group $123 \mathrm{~N}$ was relatively distinct from other race groups with $62.7 \%$ p-value in cluster II. The cluster analyses suggested that the pathogen might have a great genetic change while mutating to be virulent $\mathrm{Ht} 3$ resistant gene, but the details about the mechanisms were remain unaware.

\section{ACKNOWLEDGMENTS}

Financial research support was provided by National Natural Science Foundation of China (No. 30471126) and the Scientific and Technological Key Project from Agricultural University of Hebei. Some diseased corn leaf samples of Northern Corn Leaf Blight were favorably provided by Provincial Plant Protection Station of Heilongjiang, Jilin, Liaoning, Hebei, Shandong and Henan provinces are greatly appreciated. We thank to Dr. Jinzhuo Dong from Monsanto Co and Dr. Jian Song from Los Alamos National Laboratory of USA for critical reading of the manuscript.

\section{REFERENCES}

1. Mitra M., 1923. Helminthosporium spp. on cereals and sugarcane in India. Part I.(Diseases of Zea mays and Sorghum vulgare caused by species of Helminthosporium.). Bot. Ser. 6, pp: 219-242.

2. Gao, W, and F. Dai, 1994. A study on physiologic specialization in Exserohilum turcicum. Agricultural Sciences in China, 27(2): 90-91

3. Smith, D. R., and J. G. Kinsey, 1980. Further physiologic specialization in Helminthosporium turcicum. Plant Dis., 64: 779-781.

4. Welz, H. G., R. Wagner, and H. H. Geiger, 1993. Virulence in Setosphearia turcica populations collected from maize in China, Mexico, Uganda, and Zambia. Phytopathology, 83: 1856.

5. Chen, G., 1993. Distribution and control method of Exserohilum turcicum race 2. J. Maize Sci., 1: 65-66.

6. Wu, A., and L. Yi, 1989. Study on physiological races of Helminthosporium turcicum in Yunnan province. Yunnan Agricultural Science and Technology, 3: 18-21.

7. Yang, J. L., and B. Wang, 2002. The research advancement on genetics of resistance to Exserohilum turcicum in maize. Hereditas, 4: 501-506. 
8. Abadi, R., R. Perl-Treves, and Y. Levy, 1996. Molecular variability among Exserohilum turcicum isolates using RAPD. Canadian J. Plant Pathology, 18: 29-34.

9. Borchardt, D. S., H. G. Welz, and H. H. Geiger, 1998. Genetic structure of Setosphaeria turcica populations in temperate and tropical climates. Phytopathology, $88: 322-329$.

10. Borchardt, D. S., H. G. Welt, and H. H. Geiger, 1998. Molecular marker analysis of European Setosphaeria turcica populations. European J Plant Pathology, 104: 611-617.

11. Warren, H. L., 1975. Temperature effects on lesion development and sporulation after infection by races $\mathrm{O}$ and $\mathrm{T}$ of $B$. maydis. Phytopathology, 65: 623-626.

12. Hooker, A. L., 1963. Inheritance of chlorotic lesion resistance to Helminthosporium turcicum in seedling corn. Phytopathology, 53: 660-662.

13. Leonard, K. J., Y. Levy, and D. R. Smith, 1989. Proposed nomenclature for pathogenic races of Exserohilum turcicum. Plant. Dis., 79: 776-777.

14. An, X., J. Dong, and J. Han, 2001. RAPD analysis of Exserohilum turcicum I . CTAB method of isolating DNA from Exserohilum turcicum for RAPD. J. Agricultural University of Hebei, 24(1): 38-41.

15. Sambrook, J., E. F. Fritsch, and T. Maniatis, 1989. Molecular cloning. Cold Spring Harbor Laboratory Press, Cold Spring Harbor, New York.

16. Nei, M., and W. H. Li, 1979. Mathematical model for studying genetic variation in terms of restriction endonucleases. Proc. Natl. Acad. Sci. USA , 76: 5269-5273.

17. Sneath, P. H. A., and R. R. Sokal, 1973. Numerical taxonomy: The principles and practice of numerical classification. W. H. Freeman \& Co., San Francisco.

18. Rohlf, F. J., 1992. NTSYS-pc version 1.7. Numerical taxonomy and multivariate analysis system. Exeter Publishing, Setauket, New York.

19. Yap, I. V., and R. J. Nelson, 1996. Winboot: a program for performing bootstrap analysis of binary data to determine the confidence limits of UPGMA-based dendrograms. IRRI Discussion Paper Series No.14. International Rice Research Institute, P.O. Box 933, Manila, Philippines.

20. Leath, S., and W. L. Pedersen, 1986. Effects of the $\mathrm{HtI}$ and /or Ht3 genes in three maize inbreds on quantitative resistance to Exserohilum turcicum race 2. Plant Dis., 70: 529-531.

21. Wu, A., and L. Yi, 1989. Study on physiological races of Helminthosporium turcicum in Yunnan province. Yunnan Agricultural Science and Technology, 3: 18-21.
22. Lan, G., 1993. Identification of physiological races of Exserohilum turcicum in northwest Guizhou province. J. Southwest Agricultural Science, 6: 89-93.

23. Liu, A., and C. Zhang, 1996. A preliminary report on the monitor of physiological race of Helminthosporium turcicm in Hebei province. J. Agricultural University of Hebei, 19: 122-124.

24. Liu, G., J. Dong, F. Deng, A. Guo, F. Zhang, and M. Zang, 1996. Preliminary study on physiologic specialization and new nomenclature for Exserohilum turcicum of corn in China. Acta Phytopathologica Sinica, 26: 305-310.

25. Li, X., X. Yang, W. He, and J. Yang, 1999. Studies on constitutional variation of physiologic race of leaf blight. J. Southeast Agricultural University, 21: 37-39.

26. Ceballos, H., J. A. Deutsch, and H. Gutiérrez, 1991. Recurrent selection for resistance to Exserohilum turcicum in eight subtropical maize populations. Crop Science, 31: 964-971.

27. Shurtleff, M. C., 1980. Compendium of corn diseases. Second edition. The American Phytopathological Society, St Paul Minnesota.

28. Adipala, E., P. E. Lipps, and L.V. Madden, 1993. Reaction of maize cultivars from Uganda to Exserohilum turcicum. Phytopathology, 83: 217-223.

29. Nkonya, E., E. P. Xavery, H. Akonaay, W. Mwangi, P. Anandajasekeram, H. Verkuijl, D. Martella, and A. Moshi, 1998. Adoption of maize production technologies in Northern Tanzania. CIMMYT, The United Republic of Tanzania and Southern African Center for cooperation in Agricultural Research (SACCAR), pp: 56.

30. Tilahun, T., G. Ayana, F. Abebe, and D. Wegary, 2001. Maize pathology research in Ethiopia: a review. In: Mandefro, N., Tanner, D., and Twumasi-Afriyie, S., (ed.), Enhancing the contribution of maize to food security in Ethiopia. Proceedings of the second National workshop of Ethiopia. 12-16 November 2001, EARO and CIMMYT, Addis Ababa, Ethiopia, pp 97-105.

31. Bowen, K. L., and W. L. Pedersen, 1988. Effects of northern leaf blight and detasseling on yields and yield components of corn inbreds. Plant Dis., 72: 952-956.

32. Ferguson, L., and M. L. Carson, 2004. Spatial diversity of Setosphaeria turcica sampled from the eastern United States. Phytopathology, 94: 892-900

33. Oliari, J. B., M. A. Guimaraes, I. O. Geraldi, and E. A. Camargo, 2005. New resistance genes in the Zea mays-Exserohilum turcicum pathosystem. Genetics and Molecular Biology, 28(3): 435-439. 